\title{
Jeofizik Verilerinden Elde Edilen Sismik Zayıflık İndisinin Yapı Hasar Dağglımının Belirlenmesinde Kullanılabilirliği
}

\author{
İsmail AKKAYA* \\ Van Yüzüncü Yıl Üniversitesi, Jeofizik Mühendisliği Bölümü, Van \\ (ORCID: 0000-0002-7682-962X)
}

\begin{abstract}
$\ddot{\mathbf{O} z}$
Jeofizik yöntemlerden biri olan mikrotremor yönteminin mühendislik uygulamalarındaki kullanımı gün geçtikçe artmaktadır. Mikrotremor verilerinin spektral oranından elde edilen zemin hâkim titreşim periyodu ve büyütme değerleri kullanılarak sismik zayıflık indisi $(\mathrm{Kg})$ hesaplanabilmektedir. $\mathrm{Kg}$ zemin dinamik özelliklerine bağlı olarak değişen bir parametredir. Bu parametre ile bir alanın kuvvetli yer hareketine karşı dayanıklı veya zayıf kalma durumunun noktasal olarak değerlendirilmesi yapılabilmektedir. Çalışmada, Van yerleşim alanında 220 noktada mikrotremor ölçümleri alınarak yerleşim alanı için zayıflık indisi haritası oluşturulmuştur. Özellikle Van Gölüne yakın kesimlerde ve yapı yoğunluğunun olduğu merkez bölgelerde tehlike düzeyinin ve sismik zayıflık indisinin yüksek olduğu belirlenmiştir. 2011 Van depremi $(\mathrm{Mw}=7.1)$ sonrası bölgede incelenen binaların hasar durumları oluşturulan zayıflık indisi haritasına yerleştirilmiş ve yapıların hasar durumlarının zayıflık indeksi ile ilişkili olabileceği gözlenmiştir. Çalışma alanında özellikle Van Gölüne yakın kesimlerinde hem gevşek-suya doygun zemin yapısı hem yapı kalitesi hem de yüksek $\mathrm{Kg}$ değerlerinin elde edilmesi olası büyük bir depremde ortaya çıkabilecek yüksek ivme değerlerinde makaslama deformasyonu seviyesine bağlı zemin davranışının hasara neden olan plastik davranış ve göçme davranışına dönüşebileceği tespit edilmiştir. Elde edilen bulgular yapisal hasarlarda yapı kalitesinin yanı sıra zemin tabakalarının dinamik davranışlarının ve yerel zemin koşullarının da etkili olduğunu bir kez daha ortaya koymuştur.
\end{abstract}

Anahtar kelimeler: Mikrotremor, sismik zayıflık indisi, yapısal hasar, makaslama deformasyonu.

\section{Usability of the Seismic Vulnerability Index Obtained from Geophysical Data in Determining the Structure Damage Distribution}

\begin{abstract}
The use of microtremor method, which is one of the geophysical methods in engineering applications, is increasing day by day. Seismic Vulnerability Index $(\mathrm{Kg})$ can be calculated by using soil fundamental period and amplification values obtained from the $\mathrm{H} / \mathrm{V}$ spectral ratio of microtremor data. $\mathrm{Kg}$ is a parameter depending on the dynamic properties of soil. With this parameter, it is possible to evaluate the vulnerability of a point-based site under strong ground motion. In this study, microtremor measurements are recorded for 220 points in Van region to generate the seismic vulnerability index map. After generating the map, it is determined that hazard potential and seismic vulnerability index is high at the sites close to Lake Van and at the densely populated city center. Damage information of the buildings investigated after the 2011 Van Earthquakes (Mw=7.1) are placed on the seismic vulnerability index map and it is realized that there may be a correlation between the damage and the seismic vulnerability index. In the study area, especially in the areas close to Lake Van, it was determined that the soil behavior due to shear deformation level could be transformed into plastic behavior and collapse behavior due to high acceleration values that may occur in a large earthquake where both loose-water saturated soil structure and structure quality and high $\mathrm{Kg}$ values can be obtained. From the results of this study and the site observations, it is found that structural damages are not only structure dependent but also related to the dynamic behavior of soil layers and local soil conditions.
\end{abstract}

Keywords: Microtremor, seismic vulnerability index, building damage, shear deformation.

*Sorumlu yazar: iakkaya@yyu.edu.tr

Geliş Tarihi: 31.12.2019, Kabul Tarihi: 22.04.2020 


\section{Giriş}

Aktif tektonizma ve depremsellik etkisi altında bulunan alanlarda bölgenin deprem potansiyeli kadar, bölgedeki yapı kalitesi ve yerel zemin özellikleri de depremlerin şiddetini artıran etkenlerin başında gelmektedir. Zemin yenilmeleri, dayanım azalması, sıvılaşma, zemin büyütmesi gibi etkiler deprem dalgalarının zemin tabakalarından geçerken oluşturdukları problemler arasındadır. Dolayısıyla ülkemiz gibi deprem potansiyeli yüksek olan bölgelerde depremlere bağlı hasarlarının azaltılmasında zemin koşullarının hem statik hem de dinamik yükler altındaki davranışlarının iyi belirlenmesi gerekmektedir. Tektonizma, depremsellik, bölgesel topografik ve jeolojik koşullar deprem dalgalarının özelliklerini önemli ölçüde değiştirerek farklı derecelerde hasara yol açabilmektedir [1]. Bunun en büyük sebebi, ortamın kısa mesafelerde çok çeşitlilik göstermesi veya yerel zemin koşullarının farklılığından kaynaklanmaktadır.

Yerel zemin koşulları, yapı kalitesi ve deprem kaynak özellikleri hasarı etkileyen ana faktörlerdir ve bir arada değerlendirilmelidir. Deprem kaynak özelliklerinin, sismik dalga fazlarının, bölgesel jeoteknik koşulların ve yapı özelliklerinin, depremlere bağlı hasarlarda son derece önemli olduğu 23 Ekim 2011 (Mw=7.1) Van depremi sonrası meydana gelen yüksek hasar ve can kayıplarıyla bir kez daha ortaya çıkmıştır. Van Gölü çevresindeki yerleşim alanları genel itibariyle dağ lık alanlar ile göl arasında kalan Kuvaterner yaşlı, güncel göl ve akarsu sedimanlarının düzlükleri üzerine kuruludur ve bölge aktif tektonizmanın ve depremselliğin etkisi altındadır.

Kuvvetli yer hareketlerine maruz kalan sığ zemin tabakalarında meydana gelecek kayma şekil değiştirmesi değerlerinin bilinmesi, deprem hareketlerine bağlı yüzey etkilerinin belirlenmesinde önemli rol oynamaktadır [2]. Mikrotitreşimlerin kaydedilmesi temeline dayanan mikrotremor yönteminde üç bileşenli kayıtlar kullanılarak ölçüm noktası için zemin hakim titreşim periyodu ve büyütme değerleri belirlenir. Jeofizik saha çalışmalarında özelliklede mühendislik uygulamalarında sıklıkla kullanılan mikrotremor yöntemi aktif kaynak kullanılmaması, düşük maliyetli olması, veri toplama ekipmanlarının kolay taşınabilir ve kurulabilir olması, yoğun yerleşim alanlarında uygulama kolaylığı sağlaması, hızlı veri değerlendirme, her zaman ve her yerde ölçülebilmesinin yanı sıra geniş bir frekans bandında $(0.01-50 \mathrm{~Hz})$ enerji içermesi gibi avantajlarından dolayı son yıllarda yaygın olarak kullanılan bir yöntem olmuştur. Doğal ve yapay etkenlerden kaynaklanan, genlikleri 0.01 1 mikron arasında ve periyotları $0.05 \mathrm{~s}$ ile $2 \mathrm{~s}$ aralığında değişen yer titreşimlerine mikrotremor (titreşimcik) denir [3-5]. Bu titreşimler başlıca trafik, endüstri makineleri, rüzgâr, jeotermal reaksiyonlar, okyanus dalgaları, küçük büyüklüklü yer sarsıntıları gibi etkenler nedeniyle oluşmaktadır, gündüzleri geceden daha aktif olup dalga biçimleri düzensizdir. Bu özellikleri gözetildiğinde zemin tabakalarında kuvvetli yer hareketine bağlı oluşacak kayma deformasyonlarının belirlenmesinde mikrotremor yöntemi kullanılabilir bir yöntem olarak değerlendirilmektedir [6]. Pek çok ülke deprem mühendisliği analizleri için hem zayıf hem de kuvvetli yer hareketi özelliklerinin belirlenmesi için kayıt ağları kurmuştur. Mikrotremor ölçümleri kuvvetli yer hareketi karşısında zemin tabakalarının gösterdiği dinamik davranışı tahmin etmekte, yaygın olarak kullanılmaktadır. Mikrotremor verilerinden elde edilen büyütme değerleriyle kuvvetli yer hareketinin analizi veya zemin tabakalarının bir boyutlu dinamik analizi sonucunda hesaplanan büyütme değerlerini karşılaştıran birçok çalışma mevcuttur [6-10].

$\mathrm{Bu}$ çalışmada Nakamura [10] tarafından önerilen sismik zayıflık indisi (Kg) değerleri hesaplanarak inceleme alanı için zemin-yapı ilişkilerine bağlı hasar değerlendirmesinde mikrotremor ölçüm sonuçlarının kullanılabilirliği değerlendirilmiştir. Kg zemin dinamik özelliklerine bağlı olarak değişen bir parametredir ve zemin hakim titreşim periyodu ve büyütme değerleri kullanılarak hesaplanabilmektedir. Hesaplanan $\mathrm{Kg}$ verileriyle bir alanın kuvvetli yer hareketine karşı dayanıklı veya zayıf kalma durumunun noktasal olarak değerlendirilmesi yapılabilmektedir. Bunun için, Van ili yerleşim alanında 220 noktada mikrotremor ölçümleri alınarak yerleşim alanı için zayıflık indisi haritası oluşturulmuştur. Ayrıca, mikrotremor ölçümlerinden elde edilen kayma şekil değiştirmeleri dinamik analizlerden hesaplanan değerlerle karşılaştırılmıştır. En büyük ivme değerinin $\left(\mathrm{a}_{\max }\right)$ farklı değerlerinde yüzeye yakın zemin tabakaları için kayma şekil değiştirmeleri $\left(\gamma_{\mathrm{e}}\right)$ elde edilmiştir.

\section{2. Çalışma Alanının Genel Jeolojisi ve Depremselliği}

İnceleme alanı Van Gölünün doğusunda yer almaktadır ve Van Gölü havzası içerisinde bulunmaktadır (Şekil 1). Van Gölü havzası Geç Miyosen sonu Erken Pliyosen zaman aralığında gerçekleşen Arap ile 
Avrasya levhalarının çarpışması ile oluşmaya başlayan Doğu Anadolu Yüksek Platosu [11-12] içerisinde Geç Pliyosen'de oluşmaya başlamış ve Kuvaterner başından itibaren etkili olan volkanizmanın etkisi ile bölge son şeklini almıştır [13]. Van Gölü çevresindeki temel kaya PaleozoikMesozoyik yaşlı Bitlis Masifine ait Metamorfik kayalardır. Van Gölü’nün doğusunda, Jura kireçtaşları, Üst Kretase ofiyolitleri, Paleosen-Eosen kireçtaşları, Oligosen-Miyosen yaşlı türbidit çökelleri ve eski göl çökelleri yer almaktadır $[14,15]$. Batıda Nemrut ve Süphan, kuzeyde Etrüsk, kuzeybatıda Tendürek volkanlarına ait volkanoklastik ürünler ve lavlar geniş yayılım sunmaktadır [16]. Van Gölü’ndeki su seviyesi değişimleri göl, akarsu ve delta çökellerinin geniş yay1lım göstermesine neden olmuştur. Tüm bu birimlerin üzerinde güncel olarak sınırlı alanlarda yamaç molozu, tutturulmamış akarsu çökelleri ve yüksek yamaçlarda kolüvyal malzemeler yüzeylenmektedir $[14,15]$.

Van Gölü doğusunda yer alan Van il merkezi ve ilçeleri genellikle göl ve akarsu çökellerinden oluşan suya doygun pekişmemiş bir istif üzerinde yer almaktadır. Farklı kalınlıklara ve farklı mühendislik özelliklerine sahip olan bu sedimanlar özellikle Van Gölü'nün doğu kesimlerinde net olarak görülmektedir. Bu tür zeminler büyük depremlerde, gerek depremin tekrarlı yüklerinden, gerekse zeminden kaynaklanan deformasyonlardan büyük ölçüde etkilenmektedirler. Ayrıca, bölgedeki yapı kalitesinin de istenilen düzeyde olmaması meydana gelen depremlerde can ve mal kayıplarını arttırıcı etken olmuştur [17-23].

Kıta-kıta çarpışması neticesinde egemen olan kuzey-güney yönlü sıkışma rejimine bağlı olarak bölgedeki tektonik unsurlar genel olarak doğu-batı doğrultulu ters, kuzeybatı-güneydoğu doğrultulu sağ yönlü ve kuzeydoğu-güneybatı yönelimli sol yönlü doğrultu atımlı faylar ile kuzey-güney doğrultulu genişleme yapıları tarafindan temsil edilmektedir [12, 24-28]. Van Gölü Havzası ve çevresinde hem tarihsel hem de aletsel dönemde büyük deprem üretmiş pek çok aktif fay zonu bulunmaktadır. Bunlardan bazıları Çaldıran Fayı, Gürpınar Fayı, Alaköy Fayı, Erciş-Karayazı Fayı, Van (Everek) Fayı, Yeni Köşk fayı, Özalp fayı vb. fay zonlarıdır [25, 27-29] (Şekil 1a). Tarihsel dönemde, Van ve çevresinde 1101 ile 1900 yılları arasında V-X şiddet aralığında depremler meydana gelmiştir [30-33]. Van Gölü havzası içerisinde aletsel dönem de pek çok deprem meydana gelmiştir (Şekil 1a). Bu depremler zaman zaman can ve mal kaybına neden olmuştur. Bunlardan en önemlileri 24 Aralık 1976 Çaldıran depremi $(\mathrm{Mw}=7.3)$ ve 23 Ekim 2011 Van depremidir $(\mathrm{Mw}=7.1)$.

\section{Mikrotremor (H/V Spektral Oran, Nakamura) Yöntemi}

Nakamura [5] tarafindan geliştirilen bu yöntem tek istasyondaki mikrotremor kayıtlarının yatay bileşeninin düşey bileşene spektral oranlaması şeklinde uygulanır. Bu nedenle Nakamura yöntemi, H/V spektral oran yöntemi veya tek istasyon mikrotremor yöntemi olarak adlandırılmaktadır. Yönteminde yüzey jeolojisinden kaynaklanan yerel etki yatay ve düşey bileşenlerin spektral oranı ile bulunur. H/V yöntemi yatay bileşenlerde kayıt edilen spektral genliklerin, düşey bileşende kayıt edilen genliklere göre normalize edilme işlemi olarak tanımlanabilir. Nakamura'ya [5] göre Rayleigh dalgaları mikrotremorları oluşturan dalga türüdür ve mikrotremorların yüzeye yakın trafik, şehir gürültüleri gibi titreşimlerden oluştuğunu varsaymaktadır.

Ana kaya ile üzerindeki sediman tabakaları arasındaki empedans farkı, bir yap1 yerinde mikrotremor ölçümler ile zeminin temel rezonans frekansını belirlemede ana etkeni oluşturmaktadır. $\mathrm{Bu}$ etken kullanılarak, birbirinden farklı fiziksel yapıya sahip ortamlar arasındaki empedans farkı ve olası yerel zemin etkisi tanımlanabilir. Mikrotremor yöntemiyle ilgili teorik ve deneysel pek çok çalışma yapılmıştır $[5,7,9,10,19-23,34-49]$. 


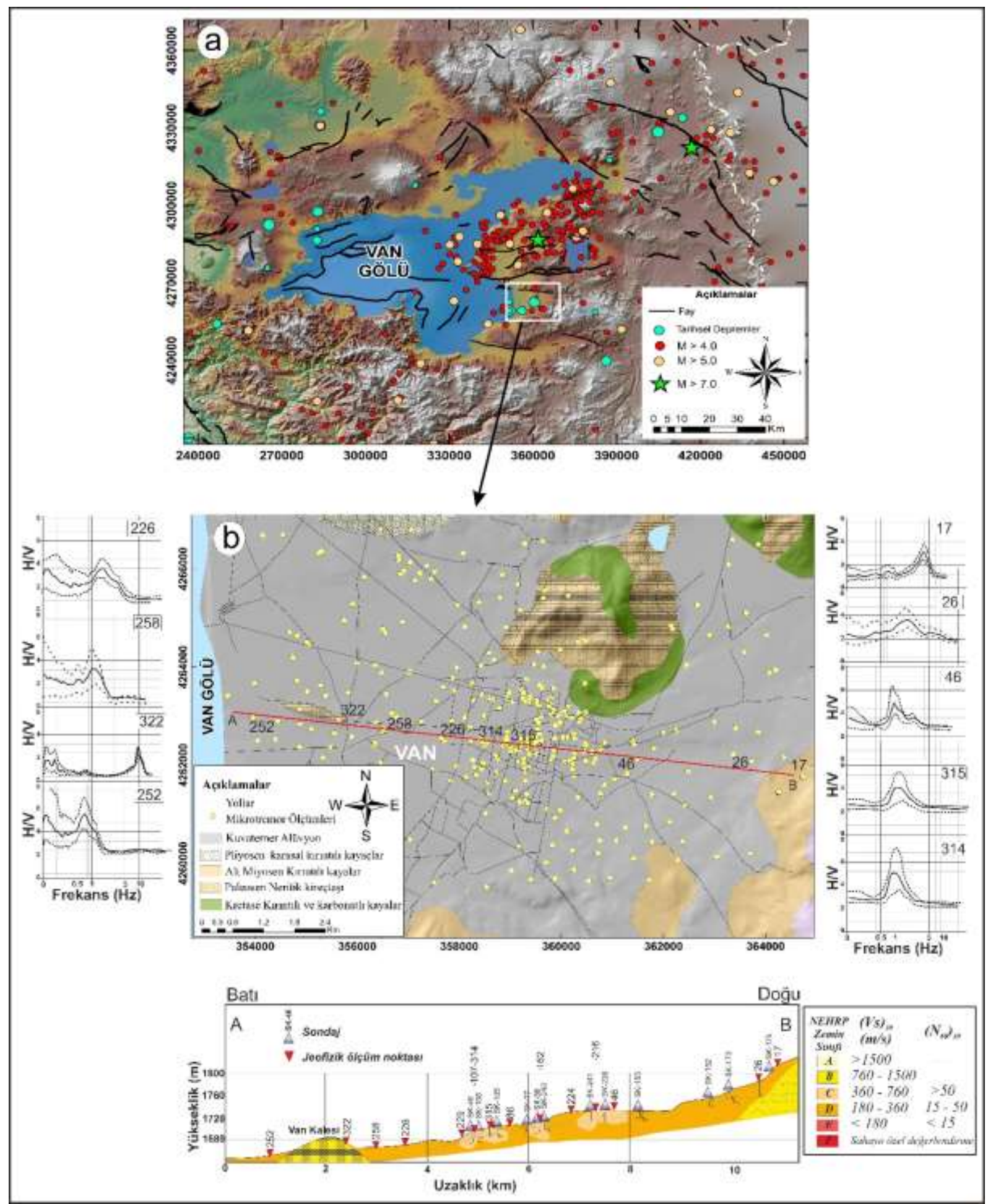

Şekil 1. Çalışma alanı ve çevresinde meydana gelen depremler ve bölgedeki faylar (a), inceleme alanındaki ölçüm noktaları ve D-B doğrultulu $\mathrm{AB}$ derinlik kesiti (b).

Çalışma alanında bölgenin baskın periyot/frekans ve büyütme değerlerinin belirlenmesi amacıyla 220 noktada tek istasyon mikrotremor ölçümleri yapılmıştır (Şekil 1b). Ölçümlerde Güralp CMG-6TD marka hızölçer mikrotremor cihazı ve ekipmanları kullanılmıştır. Mikrotremor verilerinin değerlendirilmesinde yatay bileşenin düşey bileşene spektral oranı (Nakamura Yöntemi, H/V oranı veya Tek istasyon mikrotremor) yöntemi kullanılmıştır. Mikrotremor kayıtlarında örnekleme aralığ $100 \mathrm{~Hz}$, kayıt süresi 30 ile 60 dakika seçilerek veri alınmıştır. Elde edilen veriler Scream 4.5 programı ile sayısal olarak kaydedilmiş ve Geopsy [50] yazılımı kullanılarak değerlendirilmiştir. Her bir veri zaman ortamında elde edilen üç bileşen mikrotremor kayıtlarından oluşmaktadır. Veri işlemde ilk aşamada 
mikrotremor verilerinin trend etkisi giderilmiş, ardından bant geçişli süzgeç $(0,1-20 \mathrm{~Hz})$ uygulanmıştır. Filtrelenmiş veriler 25-30 saniyelik pencerelere bölünerek \%5 cosinüs taper uygulanmıştır. Her bir pencere için Hızlı Fourier Dönüşümü (FFT) uygulanarak her bir bileşene ait genlik spektrumları elde edilmiştir (Şekil 1b). Elde edilen spektrumlara Konno-Ohmachi yuvarlatması uygulanmıştır (band genişliği 40 seçilerek). Tüm bu veri işlem adımlarının ardından yatay bileşenlerin düşey bileşene oranı hesaplanarak H/V spektral oranları elde edilmiştir (Şekil 1b).

Mikrotremor yöntemi uygulamalarında uzun süreli (en az 30 dakika) veri alınması ortamdaki geçici gürültülerin etkisinin azaltılması ve yatay-düşey spektral oranın güvenilir bir şekilde elde edilebilmesi için son derece önemlidir. Bu çalışmada, ölçümler yağışsız, rüzgârsız havalarda ve mümkün oldukça sürekli titreşim üreten yüzey gürültü kaynaklarından uzak noktalarda alınmaya çalışılmıştır. Özellikle gürültü oranının fazla olduğu yerleşim bölgelerinde mikrotremor kaydı alınırken cihaz mümkün olduğunca cihaz yüksekliği seviyesinde toprağa gömülmüş ve üzeri kutu ile kapatılmıştır. Veri değerlendirmelerinde SESAME [51] kriterleri gözetilmiştir.

\subsection{Sismik Zayıflık İndisi (Kg) ve Makaslama Deformasyonu $\left(\gamma_{\mathrm{e}}\right)$ Değerleri}

Mikrotremor verilerinden elde edilen zemin büyütmesi ve periyotla ilişkili ve yapı-zemin etkileşimi açısından önemli bir diğer parametre Sismik Zayıflık İndisi $(\mathrm{Kg})$ veya hasar indeksidir. Sismik zayıflık indisi $(\mathrm{Kg})$, zemin dinamik özelliklerine bağlı olarak değişen bir parametredir. Bu parametre ile bir alanın kuvvetli yer hareketine karşı dayanıklı veya zayıf kalma durumunun noktasal olarak değerlendirilmesi yapılabilmektedir. Doğal salınım periyodu ve genlik büyütme katsayısı ile ilişkili olan bu parametre gerek yer gerekse yapı için hesaplanabilmektedir.

Nakamura [10] tarafından önerilmiş olan $\mathrm{Kg}$, mikrotremor ölçümlerinin analizi sonucunda belirlenen büyütme ve hakim frekans değerleri kullanılarak hesaplanmaktadır ve hasar dağılımının tahmininde kullanılmaktadır. Yöntem temel olarak deprem nedeniyle oluşacak birim kayma deformasyonunun zemin hâkim frekansı ve bu frekanstaki büyütme ile ilgili olduğunu göstermektedir. Birim kayma deformasyonunun yüksek oluşu hasarı doğrudan etkileyecektir. Ana kayanın kayma dalgası hızı sabit olduğu için bu durumda hasarı başka bir deyişle oluşacak birim kayma deformasyonunu ana kayadaki ivme ve üstündeki zeminin hâkim frekansı ve büyütme değeri belirleyecektir $[9,10]$.

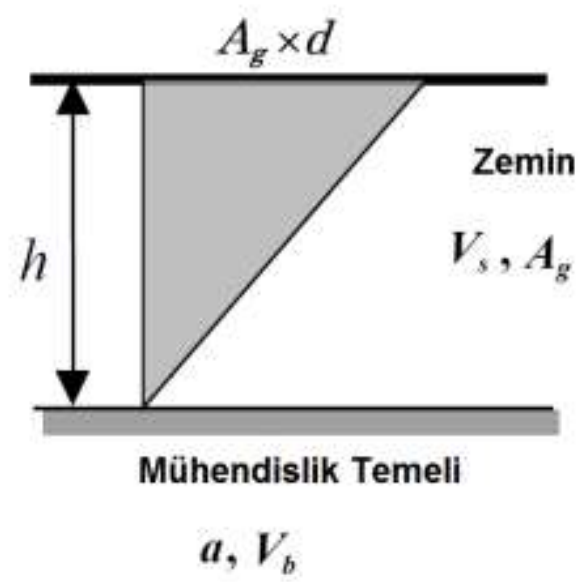

Şekil 2. Sismik Zayıflık İndisi (Kg) yer modeli [9, 10]

Deprem dalgaları farklı genlik ve frekans/periyot içeriğine sahiptir. Bu farklılık yapı ve zemin üzerinde gerilmelere neden olur. Gerilme sınırının aşılması, yapı hasarında önemli rol oynar. Nakamura [8], Kg değerinin, yıkıcı bir depremden önce hem zemin hem de deprem hasarını tahmin etmek için kullanılabileceğini öne sürmüştür. Yüzey makaslama deformasyonu $(\gamma)$ zemin tanımlamasında da yaygın olarak kullanılmaktadır. Ishihara [52] yüzey zemin deformasyonunun $\gamma \cong 10^{-3}$ değerlerinde doğrusal olmayan (plastik) davranışın, $\gamma>10^{-2}$ olduğunda ise göçme gibi büyük deformasyon olaylarına neden olduğunu belirtmiştir. 
Nakamura $[9,10]$ zemin ve yapıların olası bir deprem anında hasarını hesaplamak için Şekil 2'deki gibi bir yer modelini tasarlayarak Kg değerini önermiş̧ir. Kg hesaplaması için yüzeydeki ortalama makaslama deformasyonu $\gamma$ için;

$\gamma=A_{g} \frac{d}{h}$

eşitliği verilmiştir. Burada, $\mathrm{h}$ tabaka kalınlığı, $\mathrm{A}_{\mathrm{g}}$ zemin tabakasının sismik genlik büyütmesi, $\mathrm{d}$ ise mühendislik temelindeki sismik yer değiştirmedir. Vs zemin tabakasının, $V_{b}$ mühendislik temelinin $S-$ dalga hızı olmak üzere mühendislik temeli üzerinde yer alan zeminin baskın titreşim frekansı, Fg için $[9,10]$ :

$$
F_{g}=\frac{V_{b}}{\left(4 A_{g} h\right)}
$$

ifadesini vermiştir. Deprem nedeniyle temel kayada oluşacak a ivmesi ve d yer değiştirmesi için:

$$
\begin{aligned}
& \mathrm{a}=\mathrm{w}^{2} \mathrm{~d}=\left(2 \pi \mathrm{F}_{\mathrm{g}}\right)^{2} \mathrm{~d} \\
& \mathrm{~d}=\mathrm{a} /\left(2 \pi \mathrm{F}_{\mathrm{g}}\right)^{2}
\end{aligned}
$$

(2) ve (3) denklemleri (1) ifadesinde yazılırsa

$$
\begin{aligned}
\gamma & =\frac{\mathrm{A}_{\mathrm{g}} \alpha_{\mathrm{b}}}{\left(2 \pi \mathrm{F}_{\mathrm{g}}\right)^{2}} 4 \mathrm{~A}_{\mathrm{g}} \frac{\mathrm{F}_{\mathrm{g}}}{C_{b}} \\
& =\frac{\mathrm{A}_{\mathrm{g}}{ }^{2}}{\mathrm{~F}_{\mathrm{g}}} \frac{\alpha_{\mathrm{b}}}{\pi^{2} C_{b}} \\
& =\mathrm{c} \mathrm{K}_{\mathrm{g}} \alpha_{\mathrm{b}}
\end{aligned}
$$

elde edilir. Yüzeye yakın zemin tabakalarında kuvvetli yer hareketi sırasında oluşacak efektif makaslama deformasyonları $\left(\gamma_{\mathrm{e}}\right)$, Sismik Zayıflık İndisi $(\mathrm{Kg})$ ve sismik ana kayanın en büyük yatay ivme değerine bağlı olarak eşitlik 4 ile hesaplanabilmektedir. e, katsayısı kuvvetli yer hareketinin verimliliğini tanımlar ve deprem sırasında oluşan dinamik kuvvetin statik kuvvete oranı olarak tanımlanmış olup, $\mathrm{e}=0.60$ olarak verilmektedir [10]. Burada;

$$
\begin{aligned}
& \mathrm{c}=\frac{\mathrm{e}}{\pi^{2} \mathrm{~V}_{\mathrm{b}}} \\
& K_{g}=\frac{A_{g}{ }^{2}}{F_{g}}
\end{aligned}
$$

şeklindedir ve (5) denklemi Sismik Zayıflık İndisi olarak adlandırılır.

\section{Bulgular ve Tartışma}

Çalışma alanında 220 farklı noktalarda alınan mikrotremor ölçümlerinden zemin hâkim titreşim frekans1/periyodu, yatay-düşey genlik büyütme oranı ve Sismik Zayıflık İndisi değerleri belirlenmiş ve haritalanmıştır (Şekil 3). 
Bilindiği gibi zemin hakim titreşim periyodunun yüksek (frekansının düşük) olduğu bölgeler alüvyon kalınlığının fazla olduğu yumuşak zeminleri, titreşim periyodunun düşük (frekansın yüksek) olduğu bölgeler ise alüvyon kalınlığının az olduğu sık1/sert zeminleri veya kaya birimleri temsil etmektedir. Çalışma alanı için elde edilen zemin hakim titreşim periyotları incelendiğinde, Van ili yerleşim alanının merkez kesimlerinde ve özellikle de Van Gölüne yakın kesimlerinde yüksek titreşim periyodu değerleri (1.2-2 s), yerleşim alanının güney ve doğu kesimlerinde ise düşük titreşim periyodu $(0,3-0,1 \mathrm{~s})$ değerleri elde edilmiştir (Şekil 3a). Topoğrafyanın yükseldiği yamaç kesimlerde elde edilen periyot değerleri bu bölgelerde ana kayanın sığ derinliklerde olduğunun göstergesidir. Bölgesel jeoloji ve morfoloji incelendiğinde elde edilen bu sonuçların jeolojik yapıyla uyumlu olduğu görülmektedir.

Şekil 3b'de verilen büyütme haritası incelendiğinde ise Van Gölüne yakın kesimlerde büyütme değerinin yükseldiği görülmektedir. Aynı alanlardaki periyot değerlerinin de yüksek (Şekil 3a) olması bu kesimlerin zayıf özellikte zeminlerden oluştuğunu işaret etmektedir. Van ili yerleşim alanının güney ve doğu kesimlerinde ise büyütme değerlerinin azaldığı görülmektedir (Şekil 3b).

Çalışması kapsamında da sismik zayıflık indisi/hasar indisi $(\mathrm{Kg})$ değeri yapılan mikrotremor ölçümleri neticesinde elde edilen veriler kullanılarak, Nakamura'nın önerdiği Kg bağıntısı yardımıyla hesaplanmıştır (Eş 5, Şekil 3c). Zayıflık indeksi (Kg) haritalarında; Kg'nin 10'dan büyük değerleri için çok yüksek, 3 ’ten küçük değerleri için düşük, ara değerlerde ise orta olmak üzere sınır değerler olarak kullanılmıştır.

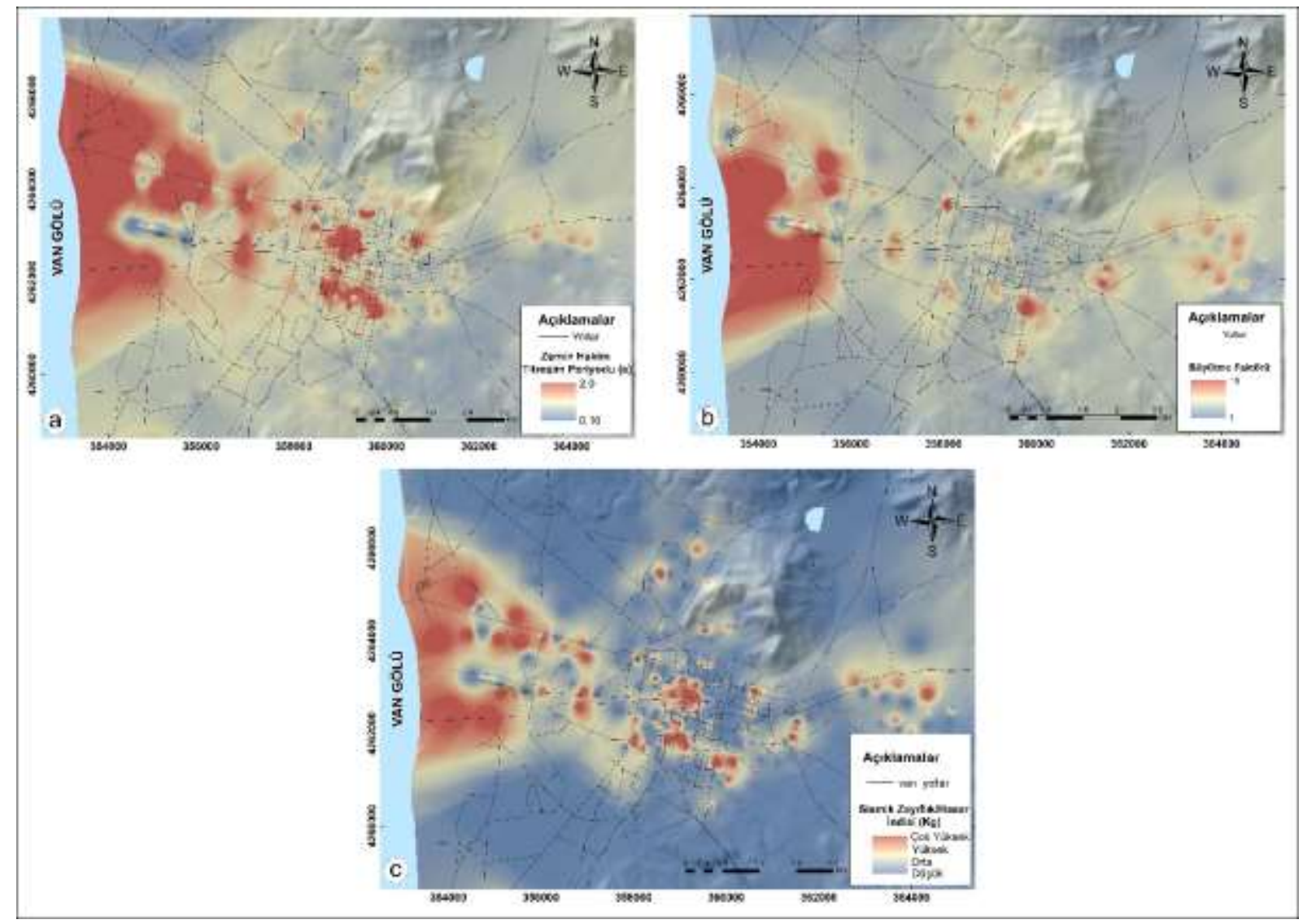

Şekil 3. Van ili yerleşim alanı ve çevresinde ölçülen mikrotremor verileri sonucu elde edilen zemin hakim titreşim periyot haritası (a), zemin büyütme haritası (b) ve sismik zayıflık indisi (Kg) haritası (c).

Çalışma alanı için hesaplanan sismik zayıflık indisi/hasar indeksi $(\mathrm{Kg})$ haritası incelendiğinde, özellikle Van Gölüne yakın kesimlerde ve yapı yoğunluğunun olduğu merkez bölgelerde sismik zayıflık indisinin yüksek olduğu belirlenmiştir (Şekil 3c).

2019 y1lında yürürlüğe giren Türkiye Bina Deprem Yönetmeliğindeki (TBDY [53]) spektral büyüklüklerin 50 yılda aşılma olasılığının \%10 ve buna karşı gelen tekrarlanma periyodunun 475 yıl olduğu seyrek deprem yer hareketini niteleyen ve standart tasarım deprem yer hareketi olarak da adlandırılan DD-2 deprem yer hareketi için hazırlanan Türkiye Deprem Tehlike Haritasında [54] Van ili yerleşim alanı ve çevresi 0.2-0.5 g ivme aralığında yer almaktadır (Şekil 4a). Bölgenin hasar 
yaratabilecek büyük deprem potansiyeli ve göreceli olarak yüksek ivmeye maruz kalma durumu çalışmada değerlendirilmiştir. Bununla birlikte 2011 Van depremlerinden sonra AFAD tarafindan incelemeleri yapılan toplam 102592 binanın \% 58.29'unun hasarsız veya az hasarlı, \% 6.44'ünün orta hasarlı, \% 20.03'ünün ağır hasarlı olduğu tespit edilmiştir (Tablo 1, Şekil 4c). Bu hasarlı bina incelemelerinin yanı sıra Van yerleşim alanı içerisindeki 188 binada da hasar değerlendirmesi yapılmış [55-57] ve Şekil 4b'de verilen sismik zayıflık indisi $(\mathrm{Kg})$ haritası üzerinde işaretlenmiştir. Şekil $4 \mathrm{~b}$ incelendiğinde mikrotremor verilerinden elde edilen $\mathrm{Kg}$ değerleriyle orta ve ağır hasarlı binaların yüksek oranda eşleştiği görülmektedir. 2011 Van depremlerinden sonra AFAD tarafindan değerlendirilen 20547 ağır hasarlı bina olduğu ve bunlarında haritaya işlendiği düşünülürse, hasarlı binalarla $\mathrm{Kg}$ arasındaki uyum daha da artacaktır. Elbette yapı hasarını etkileyen faktörlerden yerel zemin koşulları, depremin kaynak özellikleri ve yapı özellikleri bu durumu etkileyici unsurlar olarak göz ardı edilmemelidir.

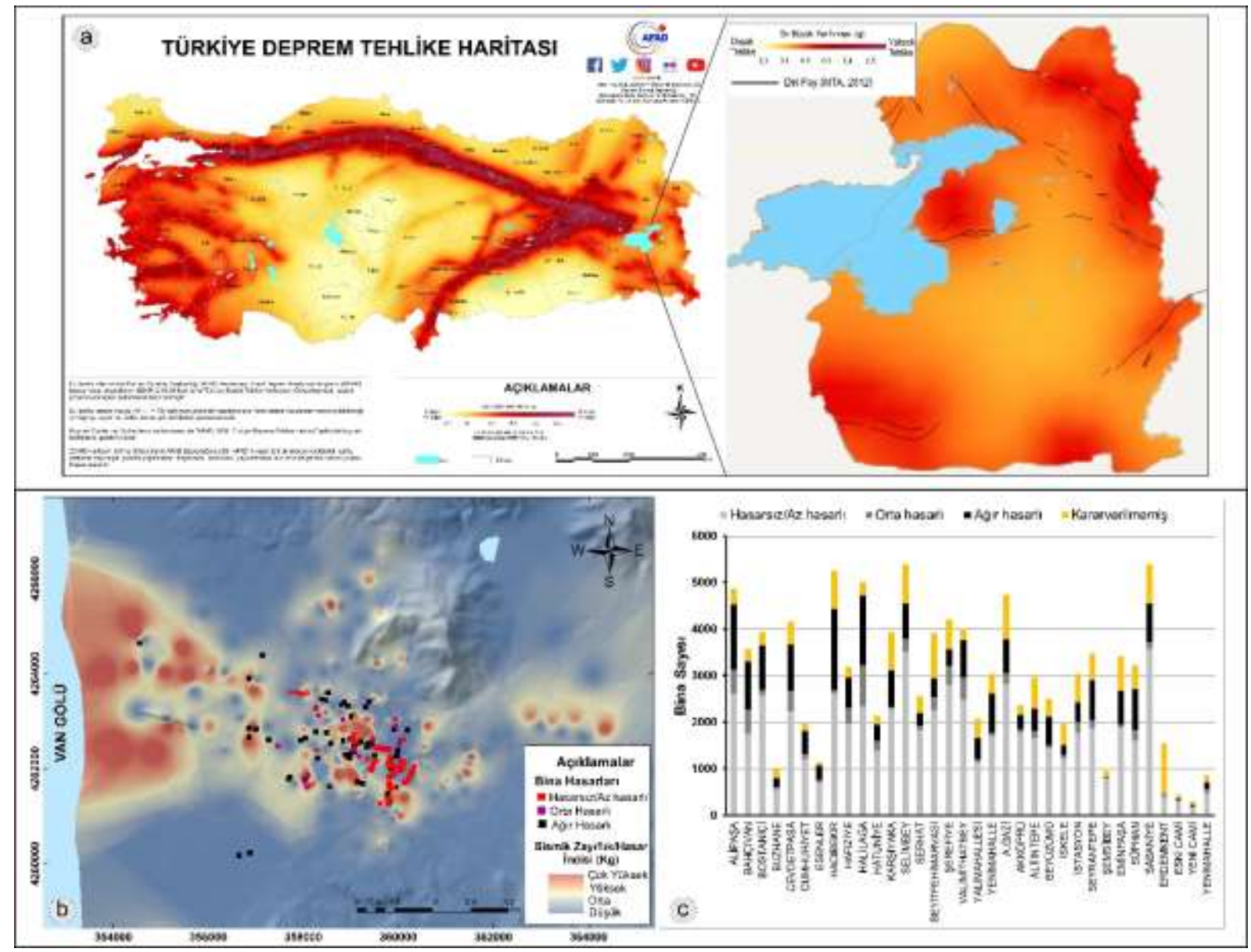

Şekil 4. Deprem Tehlike Haritası (AFAD, 2018) ve Van ili yerleşim alanı ve çevresinin tehlike haritası (a), Van ve çevresinin Sismik Hasar İndeksi ve hasarlı bina yerleri (b), 2011 Van depremi sonrası AFAD tarafindan incelenen binaların mahalle bazlı hasar durumları (c).

Tablo 1. 2011 Van Depremi Sonrası AFAD Tarafindan Değerlendirilen Binaların Hasar Durumu

\begin{tabular}{|c|c|c|c|c|c|c|c|c|}
\hline \multicolumn{2}{|c|}{ Hasarsız/Az hasarlı } & \multicolumn{2}{|c|}{ Orta hasarlı } & \multicolumn{2}{|c|}{ A ğır hasarlı } & \multicolumn{2}{|c|}{ Karar verilmemiş } & \multirow[b]{2}{*}{ Toplam } \\
\hline Bina sayısı & $\%$ Hasar & Bina sayısı & $\%$ Hasar & Bina sayısı & $\%$ Hasar & Bina sayısı & $\%$ Hasar & \\
\hline 59796 & 58.29 & 6607 & 6.44 & 20547 & 20.03 & 15642 & 15.25 & 102592 \\
\hline
\end{tabular}

$\mathrm{Bu}$ çalışmada Nakamura $[9,10]$ tarafından zeminlerin olası bir deprem anında hasarını hesaplamak için önerdiği yüzeydeki efektif makaslama deformasyonu $\left(\gamma_{e}\right)$ değerleri eşitlik 4 kullanılarak tüm mikrotremor ölçüm noktaları için hesaplanmıştır. Zemin dinamik davranış analizleri, Nakamura [10] tarafından verilen (Şekil 2) yatay tabakalı zemin modelindeki temel kayasında tanımlanan deprem yer hareketi altında doğrusal olmayan dinamik zemin özellikleri esas alınarak yapılmıştır. Mühendislik temel kaya kayma dalgası hızı $\left(V_{b}\right)$, Türkiye Bina Deprem Yönetmeliğindeki (TBDY) yerel zemin 
sınıflamasında önerildiği gibi $760 \mathrm{~m} / \mathrm{s}$ alınmıştır [53]. Eşitlik 4 kullanılarak kuvvetli yer hareketinin verimliliğini tanımlayan e katsayısı 0.60 için $C=8 \times 10^{-5} \mathrm{~s} / \mathrm{m}$ elde edilmiştir.

Çalışma alanında Şekil 1'de verilen D-B doğrultulu AB derinlik kesiti için, mikrotremor ölçümlerine göre hesaplanan $K g$ değerleri, $c$ katsayısı ile birlikte değerlendirilerek, mühendislik temel kaya ivmesinin $\left(\alpha_{b}\right) 0.15-0.40 \mathrm{~g}$ değer aralığı için yüzeye yakın zemin tabakalarındaki makaslama deformasyonları $\left(\gamma_{e}\right)$ hesaplanmış ve sonuçlar Tablo 2'de verilmiştir. TBDY'nde tekrarlanma periyodunun 475 yıl olduğu standart tasarım deprem yer hareketi için hazırlanan Türkiye Deprem Tehlike Haritasında [54] Van ili yerleşim alanı ve çevresi 0.2-0.4 g ivme aralığında yer aldığı için Tablo 2'deki hesaplamalar bu aralıkta yapılmıştır. A-B profilinde ölçülen mikrotremor analizleri sonucunda $K g$ değerleri 0.46 40.54 arasında değiştiği hesaplanmıştır. Makaslama deformasyonlarının $\left(\gamma_{e}\right)$ ise temel kaya ivmesine bağlı olarak \%0.0055 ile \%1.297 arasında değiştiği belirlenmiştir.

Tablo 2. Çalışma alanında doğu-batı doğrultulu A-B profilinde elde edilen verilerin analiz sonuçları

\begin{tabular}{|c|c|c|c|c|c|c|c|c|c|c|c|c|}
\hline \multirow{2}{*}{$\begin{array}{l}\text { Ölçü } \\
\text { No }\end{array}$} & \multirow{2}{*}{$\begin{array}{c}\text { Enlem } \\
\mathbf{X}\end{array}$} & \multirow{2}{*}{$\begin{array}{c}\text { Boylam } \\
\text { Y }\end{array}$} & \multirow{2}{*}{$\begin{array}{c}\text { Büyütme } \\
\mathbf{A}_{g}\end{array}$} & \multirow{2}{*}{$\begin{array}{c}\text { Hâkim } \\
\text { Periyot } \\
\text { t }_{0}(\mathbf{s})\end{array}$} & \multirow{2}{*}{$\begin{array}{c}\text { Sismilk } \\
\text { Zayıflık } \\
\text { İndisi } \\
\text { Kg }\end{array}$} & \multicolumn{6}{|c|}{ Makaslama Deformasyonu $\left(\gamma_{\mathrm{e}}\right)(\%)$} & \multirow{2}{*}{$\begin{array}{c}\text { Subaşı [6] } \\
\gamma_{1 \mathrm{D}}\end{array}$} \\
\hline & & & & & & $0.15 \mathrm{~g}$ & $0.2 \mathrm{~g}$ & $0.25 \mathrm{~g}$ & $0.3 \mathrm{~g}$ & $0.35 \mathrm{~g}$ & $0.4 \mathrm{~g}$ & \\
\hline 17 & 364805 & 4262270 & 2.45 & 0.30 & 1.80 & 0.0216 & 0.0288 & 0.0360 & 0.0432 & 0.0504 & 0.0576 & 0.0404 \\
\hline 26 & 363722 & 4262082 & 3.20 & 0.55 & 5.63 & 0.0676 & 0.0901 & 0.1126 & 0.1352 & 0.1577 & 0.1802 & 0.1180 \\
\hline 46 & 361520 & 4262240 & 4.62 & 1.27 & 27.11 & 0.3252 & 0.4337 & 0.5421 & 0.6505 & 0.7589 & 0.8673 & 0.5169 \\
\hline 86 & 359350 & 4262313 & 2.60 & 0.60 & 4.06 & 0.0487 & 0.0649 & 0.0811 & 0.0973 & 0.1136 & 0.1298 & 0.0867 \\
\hline 107 & 358841 & 4262395 & 3.80 & 0.74 & 10.69 & 0.1282 & 0.1709 & 0.2137 & 0.2564 & 0.2992 & 0.3419 & 0.2155 \\
\hline 162 & 359340 & 4262542 & 2.90 & 0.38 & 3.20 & 0.0383 & 0.0511 & 0.0639 & 0.0767 & 0.0895 & 0.1023 & 0.0693 \\
\hline 216 & 360441 & 4262267 & 4.20 & 0.43 & 7.59 & 0.0910 & 0.1213 & 0.1517 & 0.1820 & 0.2124 & 0.2427 & 0.1561 \\
\hline 224 & 359623 & 4262510 & 2.85 & 0.50 & 4.06 & 0.0487 & 0.0650 & 0.0812 & 0.0975 & 0.1137 & 0.1299 & 0.0868 \\
\hline 226 & 356444 & 4262824 & 3.67 & 0.50 & 6.73 & 0.0808 & 0.1077 & 0.1347 & 0.1616 & 0.1885 & 0.2155 & 0.1396 \\
\hline 229 & 358212 & 4262499 & 3.16 & 0.65 & 6.49 & 0.0779 & 0.1038 & 0.1298 & 0.1558 & 0.1817 & 0.2077 & 0.1348 \\
\hline 252 & 354448 & 4262899 & 5.50 & 1.34 & 40.54 & 0.4864 & 0.6485 & 0.8106 & 0.9727 & 1.1348 & 1.2970 & 0.7545 \\
\hline 258 & 356040 & 4262889 & 3.23 & 0.65 & 6.82 & 0.0818 & 0.1091 & 0.1364 & 0.1636 & 0.1909 & 0.2182 & 0.1413 \\
\hline 314 & 358969 & 4262661 & 4.40 & 0.90 & 17.42 & 0.2091 & 0.2788 & 0.3484 & 0.4181 & 0.4878 & 0.5575 & 0.3412 \\
\hline 315 & 358876 & 4262621 & 3.96 & 0.78 & 12.23 & 0.1468 & 0.1957 & 0.2446 & 0.2935 & 0.3424 & 0.3914 & 0.2446 \\
\hline 322 & 355647 & 4262924 & 2.04 & 0.11 & 0.46 & 0.0055 & 0.0073 & 0.0092 & 0.0110 & 0.0128 & 0.0146 & 0.0112 \\
\hline $\min$ & & & 2.04 & 0.11 & 0.46 & 0.0055 & 0.0073 & 0.0092 & 0.0110 & 0.0128 & 0.0146 & 0.0112 \\
\hline $\max$ & & & 5.50 & 1.34 & 40.54 & 0.4864 & 0.6485 & 0.8106 & 0.9727 & 1.1348 & 1.2970 & 0.7545 \\
\hline
\end{tabular}

Çalışmada ayrıca Subaşı [6] tarafından bir boyutlu eşdeğer doğrusal dinamik analizlerden elde edilen kayma birim şekil değiştirmeleri $\left(\gamma_{1 \mathrm{D}}\right)$ ile mikrotremor ölçümlerinden elde edilen makaslama deformasyonları $\left(\gamma_{\mathrm{e}}\right)$ arasında eşitlik 6 da verilen deneysel bir ilişki önerilmiştir.

$\gamma_{1 D}=5.5 \times 10^{-5}\left(\mathrm{a}_{\mathrm{b}} \mathrm{A}_{\mathrm{g}}^{2} T_{0}\right)^{0.94}$

Bağıntıda, $a_{\mathrm{b}} \mathrm{g}$ cinsinden temel kayadaki en büyük yatay ivme, $\mathrm{Ag}$ ve $\mathrm{T}_{0}$ ise mikrotremor kayıtlarından elde edilen büyütmesi ve hakim periyot değerlerini göstermektedir. Çalışma alanı için eşitlik 6 kullanılarak kayma birim şekil değiştirmeleri $\left(\gamma_{1 D}\right)$ hesaplanmıştır (Tablo 2). Kullanılan en büyük temel kaya ivme değerine göre makaslama deformasyonu seviyeleri \%0.011 0.7545 aralığında değerlere sahiptir. Ishihara [58] tarafindan verilen zemin hasarlarında oluşan makaslama deformasyonu seviyesine bağlı zemin davranışı (Tablo 3) tablosuna göre kuvvetli yer hareketi sırasında yüzeye yakın zemin tabakasında elasto-plastik davranışın etkin olacağı anlaşılmaktadır. Çalışma alanında özellikle Van Gölüne yakın kesimlerinde hem gevşek-suya doygun zemin yapısı hem yapı kalitesi hem de yüksek $\mathrm{Kg}$ değerlerinin elde edilmesi (şekil $4 \mathrm{~b}$ ) olası büyük bir depremde ortaya çıkabilecek yüksek ivme 
değerlerinde makaslama deformasyonu seviyesine bağlı zemin davranışı hasara neden olan plastik davranış ve göçme davranışına dönüşebilir.

Tablo 3. Makaslama deformasyonu seviyesine bağlı zemin davranışının değişimi (Ishihara [58]).

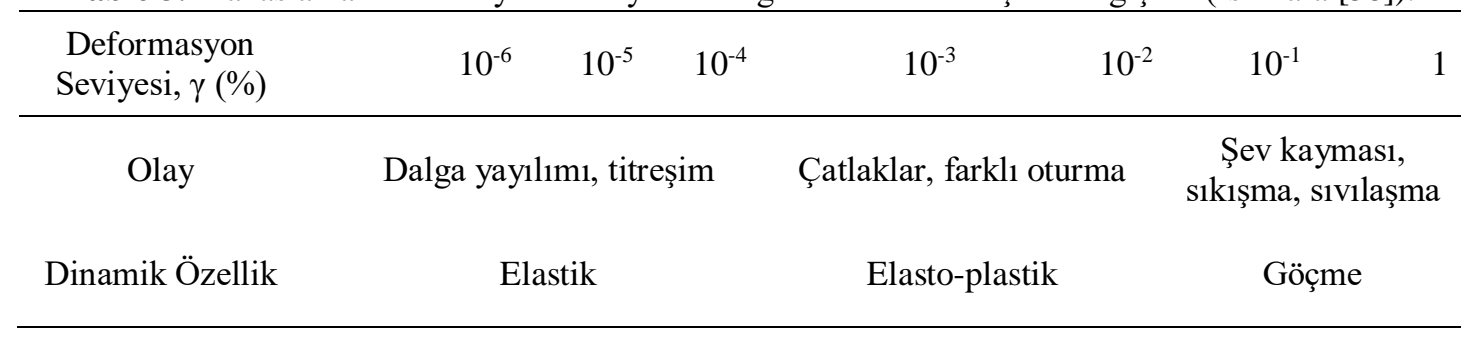

\section{Sonuç ve Öneriler}

Çalışmada, Van ili yerleşim alanı ve çevresi için mikrotremor verilerinin H/V spektral oranından elde edilen zemin hakim titreşim periyodu ve büyütme değerleri kullanılarak hesaplanan sismik zayıflık indisinin $(\mathrm{Kg})$ deprem sırasında zemin yüzeyinde oluşacak elastik davranış hakkında ön bilgi olarak kullanılabilirliği incelenmiştir. Kg değerleriyle zemin özelliklerine bağlı olarak alanın kuvvetli yer hareketine karşı dayanıklı veya zayıf kalma durumunun noktasal olarak değerlendirilmesi yapılabilmektedir. Mikrotremor verilerinden elde edilen periyot, büyütme ve Kg değerler için dağılım haritaları oluşturulmuştur. Kg değerlerinin 10'dan büyük olduğu bölgeler deprem sırasında zemin yüzeyinde dayanım kayıplarına bağlı olarak kayma ve göçme oluşabilecek alanlar olarak değerlendirilmiştir.

Büyütme haritası incelendiğinde ise Van Gölüne yakın kesimlerde büyütme değerinin yükseldiği görülmektedir. Aynı alanlardaki periyot değerlerinin de yüksek olması $(1.2-2 \mathrm{~s})$ bu kesimlerin zayıf özellikte zeminlerden oluştuğunu işaret etmektedir. Van ili yerleşim alanının güney ve doğu kesimlerinde ise büyütme ve periyot (0,3-0,1 s) değerlerinin azaldığı görülmektedir. Çalışma alanı için hesaplanan sismik zayıflık indisi/hasar indeksi $(\mathrm{Kg})$ haritası incelendiğinde, özellikle Van Gölüne yakın kesimlerde ve yapı yoğunluğunun olduğu merkez bölgelerde sismik zayıflık indisinin yüksek olduğu belirlenmiştir. 2011 Van depremi $(\mathrm{Mw}=7.1)$ sonrası bölgede incelenen binaların hasar durumları oluşturulan zayıflık indisi haritasına yerleştirilmiş ve yapıların hasar durumlarının zayıflık indeksi yüksek oranda eşleştiği görülmüştür.

Çalışmada ayrıca, zemin yüzeyindeki makaslama deformasyon değerleri hesaplanmıştır. $\mathrm{Kg}$ değerleri ile makaslama deformasyon değişimlerinin uyumlu olduğu gözlenmiştir. Mikrotremor verilerinden elde edilen $\mathrm{Kg}$ değerleri ile makaslama deformasyon değişimleri hakkında ön bilgi sağlanabileceği görülmüştür. Elde edilen bulgular yapısal hasarlarda yapı kalitesinin yanı sıra zemin tabakalarının dinamik davranışlarının ve yerel zemin koşullarının da etkili olduğunu bir kez daha ortaya koymuştur.

2011 Van depremleri sonrası bölgede hasar gören binalar gözetildiğinde yapıların hasar durumlarının zayıflık indeksi ile ilişkili olabileceği gözlenmiştir. Gerek zemin gerekse yapı zayıflık indis değeri arttıkça hasar görme derecesi de artacaktır. Bunun daha doğru olarak ortaya konulabilmesi için zemin için elde edilen bu sismik zayıflık indisinin yanı sıra yapılar içinde zayıflık indislerinin belirlenmesi gerekmektedir.

\section{Teşekkür}

Çalışamaya hem arazi aşamasında hem de düzenleme konusundaki desteklerinden dolayı Doç. Dr. Ali ÖZVAN'a, binaların hasar değerlendirmelerindeki desteklerinden dolayı Dr. Öğr. Üyesi Barış ERDIL'e, Van depremleri sonrası yapılan hasar değerlendirmelerini paylaşan AFAD Van il Müdürlüğüne ve makalenin kalitesini artıran yapıcı yorumları için hakemlere teşekkürü bir borç bilirim.

\section{Yazarların Katkısı}

Çalışmada tüm katkı yazara aittir. 


\section{Çıkar Çatışması Beyanı}

Yazarlar arasında herhangi bir çıkar çatışması bulunmamaktadır.

\section{Araştırma ve Yayın Etiği Beyanı}

Yapılan çalışmada araştırma ve yayın etiğine uyulmuştur.

\section{Kaynaklar}

[1] Ansal A. 1999. The Cyclic Behavior of Soils and Effects of Geotechnical Factors During 17 August 1999 Kocaeli Earthquake, Earthquake Hazard and Risk in the Mediterranean Region. Nicosia, 1: 89-104.

[2] Saita J., Nakamura Y., Sato T. 2012. Liquefaction caused by the 2011 off the Pacific Coast of Tohoku Earthquake and the Result of the Prior Microtremor Measurement. 15th World Conference on Earthquake Engineering, Lisboa, Portugal.

[3] Kanai K., Tanaka T. 1954. On microtremors I. Bulletion of the Earthquake Research Inst., 32: 199-209.

[4] Kanai K., Tanaka T. 1961. On Microtremors VIII. Bulletin of Earthquake Res. Inst., University of Tokyo, 39: 97-114.

[5] Nakamura Y. 1989. A Method for Dynamic Characteristics Estimation of Subsurface Using Microtremor on the Ground Surface. QR of RTRI, 30: 25-33.

[6] Subaşı O., Haşal M.E., Özaslan B., İyisan R., Yamanaka H., Chimoto K. 2019. Bir Boyutlu Dinamik Analiz ve Mikrotremor Ölçüm Sonuçlarının Karşılaştııılması. Teknik Dergi, 552: 94599481.

[7] Bard P.Y. 1998. Microtremor Measurements: A Tool for Site Effect Estimation. Proceedings of 2nd International Symposium on the Effect of Surface Geology on Seismic Motion, 1-3 Dec, Yokohama, Japan, 3: 1251-1279.

[8] Nakamura Y. 1997. Seismic Vulnerability Indices for Ground and Structures Using Microtremor. World Congress on Railway Research, Florence. Italy.

[9] Nakamura Y. 2000. Clear Identification of the Fundamental Idea of Nakamura's Technique and Its Applications. In: 12th World Conference on Earthquake Engineering, New Zealand (CDROM), Paper No. 2656.

[10] Nakamura Y. 2008. On the H/V Spectrum. The 14th World Conference on Earthquake Engineering, Beijing, China.

[11] Şengör A.M.C., Kidd W.S.F. 1979. Post-Collisional Tectonics of the Turkish-Iranian Plateau and a Comparison with Tibet. Tectonophys, 55: 361-376.

[12] Şaroğlu F., Y1lmaz Y. 1986. Doğu Anadolu'da Neotektonik Dönemdeki Jeolojik Evrim ve Havza Modelleri. MTA Genel Müdürlüğü, Jeoloji Etütleri Dairesi, Ankara.

[13] Degens E.T., Wong H.K., Kempe S., Kurtmann F. 1984. A Geological Study of Lake Van, Eastern Turkey. Geol. Rundsch, 73 (2): 701-734.

[14] Acarlar M., Bilgin A.Z., Elibol E., Erkan T., Gedik İ., Guner E., Hakyemez Y., Şen A.M., Uğuz M.F., Umut M. 1991. Van Gölü Doğusu ve Kuzeyinin Jeolojisi. MTA Rapor No. 9469, Ankara, $94 \mathrm{~s}$ (yayımlanmamış).

[15] Özvan E.E. 2019. Van/Bardakçı bölgesi zeminlerinde arazi deneyleri ve laboratuvar deneyleri arasındaki ilişkilerin belirlenmesi. Doktora Tezi, Çukurova Üniversitesi, Fen Bilimleri Enstitüsü, Adana.

[16] Yılmaz Y., Şaroğlu F., Güner Y. 1987. Initiation of neomagmatism in east Anatolia. Tectonophysics, 134: 177-199.

[17] Özvan A., Akkaya İ., Tapan M., Şengül M.A. 2005. Van yerleşkesinin deprem tehlikesi ve olas1 bir depremin sonuçları. Deprem Sempozyumu, 23-25 Mart 2005, Kocaeli.

[18] Özvan A., Şengül M.A., Tapan M. 2008. Van Gölü Havzası Neojen Çökellerinin Jeoteknik Özelliklerine Bir Bakış: Erciş Yerleşkesi. Ç.Ü. Yerbilimleri Dergisi (Geosound), 52: 297-310.

[19] Akkaya İ. 2015. The Application of HVSR Microtremor Survey Method in Yüksekova (Hakkâri) Region, Eastern Turkey. Journal of African Earth Sciences, 109: 87-95. 
[20] Akkaya İ., Özvan A., Tapan M., Șengül M.A. 2015. Determining the Site Eff ects of 23 October 2011 Earthquake (Van province, Turkey) on the Rural Areas Using HVSR Microtremor Method. Journal of Earth System Science, 124 (7): 1429-1443.

[21] Akkaya İ., Özvan A., Akın M., Akın M.K., Övün U. 2017. Kayma Dalgası Hızı (Vs) Kullanılarak Erciş (Van) Yerleşim Alanının Sıvılaşma Potansiyelinin Değerlendirilmesi. Çukurova Üniversitesi Mühendislik Mimarlık Fakültesi Dergisi, 32 (3): 55-68.

[22] Akkaya İ., Özvan A., Akın M., Akın M.K., Övün U. 2018. Comparison of SPT and Vs-Based Liquefaction Analyses: A Case Study in Erciş (Van, Turkey). Acta Geophysica, 66: 21-38.

[23] Akkaya İ., Özvan A. 2019. Site Characterization in the Van Settlement (Eastern Turkey) Using Surface Waves and HVSR Microtremor Methods. Journal of Applied Geophysics, 160: 157-170.

[24] Bozkurt E. 2001. Neotectonics of Turkey-a Synthesis. Geodin. Acta, 14: 3-30.

[25] Koçyiğit A., Yilmaz A., Adamia S., Kulashvili S. 2001. Neotectonics of East Anatolian Plateau (Turkey) and Lesser Caucasus: Implication for Transition from Thrusting to Strike-Slip Faulting. Geodinamica Acta, 14: 177-195.

[26] Cukur D., Krastel S., Tomonaga Y., Schmincke H-U., Sumita M., Meydan A.F., Cagatay M.N., Toker M., Kim S-P., Kong G-S., Horozal S. 2016. Structural Characteristics of the Lake Van Basin, Eastern Turkey, from High-Resolution Seismic Reflection Profiles and Multibeam Echosounder Data: Geologic and Tectonic Implications. Int. J. Earth Sci. (Geol Rundsch), http://dx.doi.org/10.1007/s00531-016-1312-5.

[27] Emre Ö., Duman T.Y., Özalp S., Elmacı H., Olgun Ş., Şaroğlu F. 2013. 1/1.250.000 Ölçekli Türkiye Diri Fay Haritası, Maden Tetkik ve Arama Genel Müdürlüğü Özel Yayınlar Serisi, Ankara, Türkiye.

[28] Selçuk A.S. 2016. Evaluation of the Relative Tectonic Activity in the Eastern Lake Van Basin, East Turkey. Geomorphology, 270: 9-21.

[29] Toker M., Şengör A. M.C., Demirel-Schlueter F., Demirbăg E., Çukur D., İmren C., Niessen F., PaleoVan-Working Group. 2017. The Structural Elements and Tectonics of the Lake Van basin (Eastern Anatolia) from Multi-Channel Seismic Reflection Profiles. Journal of African Earth Sciences, 129: 165-178.

[30] Ergin K., Güçlü U., Uz Z. 1967. Türkiye ve Civarının Deprem Kataloğu (MS. 11-1964), İstanbul. İstanbul Teknik Üniversitesi Maden Fakültesi Arz Fiziği Enstitüsü yayınları, No: 28.

[31] Soysal H., Sipahioğlu S., Kolçak D., Altınok Y. 1981. Türkiye ve Çevresinin Tarihsel Deprem Kataloğu (2100 B.C.-1900 A.D.). TÜBİTAK raporu, No: TBAG-341.

[32] Ambraseys N.N., Finkel C.F. 1995. The Seismicity of Turkey and Adjacent Areas: A Historical Review, 1500-1800, İstanbul. Eren publishing \& booktrade.

[33] Tan O., Tapırdamaz M.C., Yörük A. 2008. The Earthquakes Catalogues for Turkey. Turkish Journal of Earth Science, 17: 405-418.

[34] Field E.H., Jacob K.H. 1993. The Theoretical Response of Sedimentary Layers to Ambient Seismic Noise. Geophys Res Lett., 20-24: 2925-2928.

[35] Field E.H., Jacob K.H. 1995. A Comparison and Test of Various Site-Response Estimation Techniques, Including Three That are not Reference-Site Dependent. Bull. Seismol. Soc. Am., 85 (4): 1127-1143.

[36] Lermo J., Chavez-Garcia F.J. 1994. Are Microtremors Useful in Site Response Evaluation? Bulletin of the Seismological Society of America, 84: 1350-1364.

[37] Lachet C., Bard P.Y. 1994. Numerical and Theoretical Investigations on the Possibilities and Limitations of Nakamura's Technique. Journal of Physics of the Earth, 42: 377-397.

[38] Gitterman Y., Zaslavsky Y., Shapira A., Shtivelman V. 1996. Empirical Site Response Evaluations: Case Studies in Israel. Soil Dynamics Earthquake Engineering, 15: 447-463.

[39] Mucciarelli M. 1998. Reliability and Applicability of Nakamura's Technique Using Microtremors: An Experimental Approach. Journal of Earthquake Engineering, 2: 1-14.

[40] Konno K., Ohmachi T. 1998. Ground-Motion Characteristics Estimated from Spectral Ratio Between Horizontal and Vertical Components of Microtremor. Bulletin of the Seismological Society of America, 88: 228-241.

[41] Delgado J., Lopez Casado C., Giner J., Estevez A., Cuenca A., Molina S. 2000. Microtremors as a Geophysical Exploration Tool: Applications and Limitations. Pure and Applied Geophysics, 157: $1445-1462$. 
[42] Okada H. 2003. Microtremor Survey Method. SEG Geophysical Monograph Series No. 12, (translated by Koya Suto), Society of Exploration Geophysicists.

[43] Dikmen Ü., Mirzaoğlu M. 2005. The Seismic Microzonation Map of Yenisehir-Bursa, NW of Turkey by Means of Ambient Noise Measurements. Balkan Geophysical Society, 8 (2): 53-62.

[44] Özalaybey S., Zor E., Ergintav S., Tapırdamaz M.C. 2011. Investigation of 3-D Basin Structures in the İzmit Bay Area (Turkey) by Single station Microtremor and Gravimetric Methods. Geophysical Journal International, 186: 883-894.

[45] Pamuk E., Akgün M., Özdağ Ö.C., Gönenç T. 2017. 2D Soil and Engineering-Seismic Bedrock Modeling of Eastern Part of Izmir Inner Bay/Turkey. Journal of Applied Geophysics, 137: 104117.

[46] Pamuk E., Özdă̆ Ö.C., Özyalın Ş., Akgün M. 2017. Soil Characterization of Tınaztepe Region (İzmir/Turkey) Using Surface Wave Methods and Nakamura (HVSR) Technique. Earthquake Engineering and Engineering Vibration, 16 (2): 447-458.

[47] Silahtar A., Budakoğlu E., Horasan G., Yıldırım E., Küyük H.S., Yavuz E., Çaka D. 2016. Investigation of Site Properties in Adapazar1, Turkey, Using Microtremors and Surface Waves. Environ Earth Sci, 75: 1354, DOI 10.1007/s12665-016-6151-y.

[48] Tün M., Pekkan E., Özel O., Güney Y. 2016. An Investigation into the Bedrock Depth in the Eskisehir Quaternary Basin (Turkey) Using the Microtremor Method, Geophys. J. Int., 207: 589607.

[49] Livaoğlu H., Irmak T.S., Güven I.T. 2017. Seismic Vulnerability Indices of Ground for Değirmendere (Kocaeli Province, Turkey). Bull Eng Geol Environ, DOI 10.1007/s10064-0171102-8.

[50] GEOPSY 1997. Geophysical Signal Database for Noise Array Processing, www.geopsy.org (Erişim Tarihi: 10.07.2018).

[51] SESAME 2004. Guidelines for the Implementation of the H/V Spectral Ratio Technique on Ambient Vibrations: Measurements, Processing and Interpretation SESAME European Research Project P12-Deliverable. D23.12 ftp://ftp.geo.uib.no/pub/seismo/Software/Sesame/ Userguidelines/Sesame-HV-UserGuide lines.doc.

[52] Ishihara K. 1982. Evaluation of Soil Properties for Use in Earthquake Response Analysis. Proc. International Symp. On Num. Model in Geomechanics, 237-259.

[53] Türkiye Bina Deprem Yönetmeliği (TBDY) 2018. Afet ve Acil Durum Yönetimi Başkanlığ1, Ankara.

[54] AFAD 2018. Türkiye Deprem Tehlike Haritası. https://tdth.afad.gov.tr/ (Erişim Tarihi: 20.12.2019).

[55] Erdil B., Ceylan H. 2019. MVP Interaction Based Seismic Vulnerability Assessment of RC Buildings. Gradevinar, 71: 489-503.

[56] Erdil B., Ceylan H. 2019. A Detailed Comparison of Preliminary Seismic Vulnerability Assessment Methods for RC Buildings. Iranian Journal of Science and Technology-Transactions of Civil Engineering, 43: 711-725.

[57] Akkaya İ. 2020. Availability of Seismic Vulnerability Index (Kg) in the Assessment of Building Damage in Van, Eastern Turkey. Earthquake Engineering and Engineerıng Vibration, 19: 189204.

[58] Ishihara K. 1996. Soil Behaviour in Earthquake Geotechnics. Oxford Engineering Science Series, Oxford University Press, U.K. 